\title{
PERFIL ALIMENTAR E ESTADO NUTRICIONAL DE CRIANÇAS NO PRIMEIRO ANO DE VIDA
}

\section{Marisa da Silva Corrêa ${ }^{1}$ \\ Aline Carare Candido ${ }^{2}$ \\ Tainara Valadares Turino ${ }^{3}$ \\ Fabiana de Cássia Carvalho Oliveira ${ }^{4}$}

Resumo: O leite materno é a base alimentar do lactente, devendo ser oferecido de maneira exclusiva nos primeiros seis meses de vida e mantido até os dois anos de idade ou mais. O presente estudo teve como finalidade avaliar o perfil alimentar e estado nutricional de crianças no primeiro ano de vida. Para tal fim, foram captadas crianças de 0 a 12 meses atendidas na Clínica Escola de Nutrição da UFES/Alegre-ES. O perfil alimentar foi avaliado qualitativamente e o estado nutricional através das medidas de peso e comprimento, convertidos nos índices peso/idade, comprimento/idade e Índice de Massa Corporal/ldade. O estudo contemplou 34 lactentes com idade entre 10 dias e 1 ano, sendo 56\% do sexo feminino. Verificouse que $14,7 \%$ apresentavam risco de sobrepeso ou sobrepeso, $82,35 \%$ dos lactentes consumia leite materno exclusivamente ou com fórmula infantil, 66,6\% das mães introduziram alimentos com 6 meses e $10 \%$ das crianças já havia consumido refrigerante, biscoito recheado e bolos artificiais no primeiro ano de vida. Faz-se necessária conscientização das mães quanto à introdução alimentar infantil.

Palavras-chave: Lactente; Perfil alimentar, Estado nutricional; Aleitamento materno; Introdução alimentar.

\footnotetext{
${ }^{1}$ Nutrição/Universidade Federal do Espírito Santo, Campus Alegre-ES, Brasil. E-mail: marisa.correanutri@gmail.com.

${ }^{2}$ Nutrição/Universidade Federal do Espírito Santo, Campus Alegre-ES, Brasil. E-mail: alinecarrare@hotmail.com. ${ }^{3}$ Nutrição/Universidade Federal do Espírito Santo, Campus Alegre-ES, Brasil, E-mail: tainara.turino@gmail.com. ${ }^{4}$ Nutrição/Departamento de Farmácia e Nutrição, Universidade Federal do Espírito Santo, Campus Alegre-ES, Brasil. E-mail: fadcco@gmail.com.
} 